Moss, G., \& Colman, A. M. (2001). Choices and preferences: Experiments on gender differences. Journal of Brand Management, 9, 89-98.

\title{
Choices and Preferences: Experiments on Gender Differences
}

\section{Gloria Moss}

Address: 53 Asmuns Place, London NW11 7XE, UK;

Tel/Fax: +441814582879

\section{Andrew M. Colman}

Address: School of Psychology, University of Leicester, Leicester LE1 7RH, UK;

Tel: +44 1162522170

Gloria Moss is a Director of Product Psychology, a consultancy specialising in tailoring consumer products and services to specific market segments. Formerly Training Manager (UK) with Eurotunnel, and before that Site Training Manager with Courtaulds at Britain's largest manufacturing site, she has been an Associate Lecturer for many years with the Open University Business School.

Andrew M. Colman is Professor of Psychology at the University of Leicester. His research focuses mainly on decision making, and he has also investigated aesthetic preferences and consumer preferences for services. His contribution to this article was facilitated by study leave granted by the University of Leicester. 


\section{ABSTRACT}

Gender differences in consumer choices and preferences were explored in two quasiexperiments. In Experiment I, business cards were collected from 144 men and 83 women attending a Young Designers exhibition. The business cards of male designers were found to be of standard size and printed on white card significantly more often than the cards of female designers. In Experiment II, 35 female and 30 male respondents indicated which of four representative Christmas cards they preferred. A significant tendency was found for respondents to choose cards designed by members of their own sex. These findings are discussed in relation to earlier research into gender differences, and implications for design and brand management are outlined.

\section{THE CUSTOMER'S POINT OF VIEW}

A classic marketing textbook, ${ }^{1}$ written almost fifty years ago, suggested that successful marketing involves seeing the business from the customer's point of view, and in today's commercial environment the same could be said with equal force about successful brand management. One possible route into the customer's mind, often recommended in the literature, is the study of market segmentation variables. They provide a method of identifying subgroups of consumers who are likely to respond in a relatively homogeneous way to products/services or brands. ${ }^{2}$ Gender is almost invariably cited as an important segmentation variable, but in fact relatively little research had been carried out until recently to establish whether men's and women's responses to consumer products and brands differ systematically. Some publications have discussed informally techniques of marketing specifically to women, ${ }^{3}$ but gender differences have surprisingly seldom been addressed in relation to consumer or brand preferences in the published research literature.

In particular, very little research has been devoted to gender differences in design preferences. Aside from some earlier work by the first author of this article, ${ }^{4}$ researchers have failed to examine whether, and if so how, the design preferences of men and women -- their evaluative responses to the appearance of products or associated images -- may differ. In this 
article we hope to make a contribution towards filling this gap in the research literature by reporting the results of two new investigations designed to examine gender differences in consumer choices and preferences. The quasi-experimental research design used in both investigations was the nonequivalent group design. ${ }^{5}$ The two experiments focus on business cards and Christmas cards respectively.

\section{EXPERIMENT I: BUSINESS CARDS}

All the business cards available at a Young Designers exhibition in London, an annual event bringing together graduates from design schools across the United Kingdom, were collected. This yielded a total of 227 business cards, 144 from women and 83 from men. The sample was homogeneous in the sense that the cards belonged to people of similar levels of attainment, with similar training backgrounds, and they all related to a common theme.

According to informal enquiries at print shops, the standard size for business cards is 85-90 $\mathrm{cm}$ long and 50-55 cm wide, and the normal practice (again according to print shops) is for the text and/or graphics to be printed on to white card. We used two relatively unambiguous attributes of the cards -- their sizes and colours -- in comparing the male and female cards. This enabled relatively straightforward and objective comparisons to be made without significant risk of experimenter effects. ${ }^{6}$

\section{Procedure}

For each of the 227 cards, the experimenter simply noted (a) whether it was from a male or a female designer; (b) whether or not it fell within the standard size parameters; and (c) whether it was printed on white or coloured card. The first author performed this exercise twice, to check the reliability of the procedure, and no differences were found between the two sortings.

\section{Results}

Turning first to the sizes of cards, 54 per cent of the cards from male designers turned out to 
be within the standard size parameters, compared with 38 per cent of the female cards. A chisquare test of association with one degree of freedom yielded a chi-square value of 5.77 and an associated significance level of $p<0.02$. This indicates that the difference between the proportions of male designers and female designers with standard-size cards was statistically significant.

As regards the colours of the cards, 74 per cent of the male designers used white card, compared with 53 per cent of the female designers. A chi-square test with one degree of freedom yielded a chi-square value of 8.90 and an associated significance level of $p<0.01$. This shows that the difference between the proportions of male and female designers using white cards was also statistically significant. Figure 1 shows a representative card from a male designer (a) and a representative card from a female designer (b), taken from the collection used in the experiment.

Figure $1(\mathrm{a}, \mathrm{b})$ about here

\section{Conclusions of Experiment I}

The findings show that business cards chosen or designed by male designers are more likely than those chosen or designed by female designers to be of standard dimensions and to be printed on white card. The finding that women were more interested in colour than men finds parallels in data from previous research in which women have shown a greater interest in and adventurousness with colour. ${ }^{7}$ The female choices of non-standard sizes may reflect a greater willingness among women to put aesthetics above practical considerations and form above function, for which there is also some evidence. ${ }^{8}$ We shall return to these issues later in the article.

\section{EXPERIMENT II: CHRISTMAS CARDS}

The greetings card industry in the UK was worth $£ 1.1$ bn in $1999 .{ }^{9}$ British citizens spend 
more per capita on cards than any other nation -- on average, approximately £22.33 per capita per annum on greeting cards of all kinds. The popularity of greeting cards in the UK may be linked to the fact that the first commercially produced Christmas cards were commissioned in 1843 by Sir Henry Cole, founder of the Victoria and Albert Museum. As a result of his commission, cards designed by J. C. Horsley were widely distributed in the immediately following years. Today, of the various types of greeting cards sent, Christmas cards represent the bulk in terms of volume, comprising as they do 64.4 per cent of all greeting cards sent. According to Keynote market research, most greetings cards are bought by women ${ }^{10}$. In order to compare male and female preferences for Christmas cards, we performed the following simple experiment.

\section{Procedure}

Four Christmas cards were selected on the basis of the following criteria:

(1) The four cards depicted the same or similar themes;

(2) The name of the artist/designer was indicated on or visible through the packaging;

(3) Two of the artists/designers were male, and two were female.

Of all the cards available in December 2000, we were able to find only four that fulfilled these criteria. They included three cards depicting a Christmas tree and a fourth depicting an outdoor snow-filled scene, the common theme being Christmas vegetation. The four cards are shown in Figure 2: the artist or designer was male in (a) and (b) and female in (c) and (d).

Figure 2 (a, b, c, d) about here

The four cards were shown separately to 35 female and 30 male respondents, each of whom was asked to indicate which of the four cards he or she preferred. The respondents 
were unaware of the sex of the designers and the fact that the experiment was concerned with gender issues. The respondents were a convenience sample people encountered adventitiously over a period of week. They included librarians in a local reference library, assistants in shops (newsagents and dry cleaners), acquaintances (including their children), and people attending a charity function.

\section{Results}

The preferences of the male and female respondents are shown in Table 1. It is clear from these data that there was a strong tendency for respondents to prefer Christmas cards designed by members of their own sex. A chi-square test of association yielded a chi-square value of 11.45, with an associated significance level of $p<0.001$. This confirms that there was a highly significant bias towards same-sex preferences.

Table 1 about here

\section{Conclusions of Experiment II}

The results of Experiment II reveal a strong tendency for both men and women to prefer designs produced by members of their own sex. This supplements evidence from earlier investigations. ${ }^{11}$

Although the sample was merely a convenience sample, without pretensions to statistical representativeness, it included people of varying nationalities (English, Scottish, Indian, Turkish, Algerian, German, Italian, and American); a wide range of ages (children and adults); and varied occupations (shopkeepers, librarians, lawyers, psychologists, business consultants, secretaries, and entrepreneurs). It has been pointed out by several authorities on research methodology (e.g., Dane, ${ }^{12}$ pp. 84-85) that convenience and opportunity samples are adequate for 'broad-brush' investigations of gender differences. In addition, the heterogeneity of the sample makes it more representative than the student-only opportunity and 
convenience samples used in the vast majority of standard psychology experiments. ${ }^{13}$ Furthermore, 'deliberate sampling for heterogeneity' is a recognised technique for increasing external validity in this type of research. ${ }^{14}$

\section{EXPLAINING THE DIFFERENCES}

Experiment I, which focused on business cards, showed the extent to which the objects created or chosen by men and women can differ. The fact that the cards from male designers were significantly more often of standard size and significantly more likely to be printed on a white background than cards from female designers suggests that men are more prone to follow convention where business cards are concerned. Previous experiments have revealed similar differences, with female graphic designs tending to be more colourful, less technical, less linear, and less three-dimensional than male designs. ${ }^{15}$ Moreover, other researchers have revealed a significant tendency, in drawings of human forms, for people to draw members of their own sex. ${ }^{16}$ Interviews carried out with people in design and marketing ${ }^{17}$ have revealed that men may be more concerned with function than aesthetic attributes, and vice versa for women.

Table 2 about here

Summarising all these findings, the major differences between male and female design preferences are as shown in Table 2. The interpretation and explanation of these differences is a matter of controversy. Some of the factors that may be involved are discussed below.

\section{PSYCHOLOGY OF GENDER DIFFERENCES}

In contemporary (especially feminist) psychology, sex differences, the biological differences between male and female forms, are sometimes distinguished from gender differences, the behavioural, social, and cultural differences associated with sex differences. When a baby is 
born, anatomy determines its sex, whereas 'the pink or blue blanket that soon enfolds the baby represents gender' 18

In 1974, an influential review of published psychological research up to that time ${ }^{19}$ concluded that only a few consistent gender differences had been established, namely significantly greater aggressiveness in males and significant male superiority at mathematical and visuo-spatial tasks. Since then, a huge amount of research has been published, and some of the originally identified gender differences, such as the male superiority at mathematical tasks, appear to have been decreasing and possibly disappearing, at least in the United States. ${ }^{20}$ On the other hand, numerous other gender differences have been identified, including significantly more intense emotional responses in women, and female superiority at decoding non-verbal communication or body language, ${ }^{21}$ even in young children. ${ }^{22}$ Differences in visuo-spatial abilities have turned out to be among the most robust. ${ }^{23}$

The interpretation and explanation of gender differences is a hotly debated issue in contemporary psychology. They may reflect the differential social roles that men and women have historically tended to occupy in most societies. Alternatively or additionally, they may reflect evolutionary adaptations arising from the biologically determined child-bearing and nurturing functions of women.

Although the origins of gender differences remain obscure, perceptions or stereotypes of such differences are remarkably distinct and uniform across cultural boundaries. One team of researchers ${ }^{24}$ asked respondents in 25 different countries across the world to choose from a checklist of 300 adjectives (such as aggressive, artistic, bossy) those that were characteristic of either men or women. In every one of the 25 cultures in which these data were collected, women were judged by a majority of respondents to be sentimental and submissive, whereas men were judged to be adventurous, dominant, and forceful, and in 24 of the 25 cultures women were judged to be affectionate and sensitive, whereas men were judged to be aggressive. Whatever their origin, these stereotypes, nowadays referred to in the psychological literature as gender schemas, ${ }^{25}$ are well-defined, firmly established, and ubiquitous. 


\section{Gender differences in design preferences}

It seems likely that the gender differences in design preferences reported in this article and in earlier research are related to other, underlying gender differences. One possibility is that personality differences between men and women, such as those embodied in the gender schemas discussed immediately above, are reflected in gender differences in design preferences. For example, if women do indeed tend to be more sentimental and submissive in personality, and men more dominant and forceful, then these personality differences could perhaps underlie some of the differences shown in Table 2, with forcefulness being expressed in a preference for linearity, perhaps.

A second possibility is that the well-established gender differences in visuo-spatial performance might account for some of the differences in design preferences. For example, male preferences for technicality and three-dimensionality in design may be attributable to relative male facility at visuo-spatial imagery, ${ }^{26}$ and female interest in colour to superior female colour vision -- a significant proportion of men, but far fewer women, suffer from some degree of colour blindness. ${ }^{27}$

Third, the different cultural experiences of men and women may play a significant role. Experimental evidence has established that, other things being equal, familiarity for objects of all kinds tends to lead to increased liking for them, ${ }^{28}$ at least up to a very high level of familiarity. ${ }^{29}$ Men may therefore tend to prefer standard-sized business cards with white backgrounds more than women partly because they are more likely to have had experience of such objects during the process of socialisation, or because of greater exposure to conventional or formal working environments than women. The gender differences in preferences for Christmas cards may also be influenced partly by such cultural effects, assuming that the socialisation of boys and girls tends to differ and that familiarity tends to increase liking.

Most of the other gender differences shown in Table 2 could be influenced by familiarity effects, even if their ultimate origins are biological. The reported male preference 
for linearity, technicality, three-dimensionality, and functionality in design may reflect the fact that these attributes are more characteristic of male than female toys and other cultural objects, and familiarity may lead to liking. The greater female interest in colour may reflect the fact that female toys and other cultural objects are more often brightly coloured than their male counterparts, even if that is ultimately due to biological differences in colour vision. The fact that representations of human forms by both sexes tend to be biased towards samesex representations can obviously be explained in the same way: other things being equal, people tend to choose what they know best -- 'I know what I like' can often be translated as 'I like what I know'.

The cultural explanation is speculative, however, and it merely pushes the problem back one step. It remains to be explained why toys and other cultural objects tend to be gender-typed in the way that they are. The fact that men may have a greater tendency than women to value functionality over aesthetics, for example, may well be explained by their greater exposure to functional objects throughout the socialisation process, but that does not explain very much, because the male gender-typing of functionality remains unexplained. The underlying gender differences are certainly not well understood and merit further research.

\section{IMPLICATIONS FOR DESIGN AND BRAND MANAGEMENT}

Marketing and brand management involve seeing things from the customer's point of view, and design is an important ingredient of the marketing and brand management mix. One is therefore entitled to question whether design decisions by members of one sex are likely to produce optimum solutions when members of the target market are of the opposite sex. The fashion designer George Davies was recently hired by Marks and Spencer in the UK to design a range of clothes for women in the 25 to 35 year age range, and he was quoted as saying: 'I have studied the whole psychology of women'. ${ }^{30}$ Although his motivation, and indeed his abilities, are beyond question, it may nevertheless be the case that female designers are in a better position to get into the minds of female consumers. 
A key issue is whether a man (or a woman, for that matter), is as likely as someone of the same sex to gain a deep understanding of the product/service and brand preferences of members of the opposite sex, other things being equal. Most successful designers of women's clothes are undoubtedly men, but the question remains: can one design as effectively for the opposite sex as for one's own? The responses of men and women to the Christmas cards used in Experiment II suggests not. Women showed strong preferences for the designs of women, and men for the designs of men. In the light of this, coupled with the fact that women buy more cards than men, it seems appropriate that the majority of greetings and Christmas cards should be the work of female designers, and it would probably be worthwhile for the fashion industry to employ more women designers.

The case of Motorola mobile telephones provides a salutary lesson for designers and brand managers. According to an unpublished research paper by the American investment broker Piper-Jaffray -- a company that normally talks the language of accounting -Motorola’s loss of market share was directly related to its failure to provide coloured handsets. Its only concession to those customers who found the all-black handsets rebarbative was to add a touch of chrome, a characteristically American design solution with roots in the automotive industry.

If Motorola or any other telephone producer decides to use colour, whose colour preferences does it follow, men's or women's? Our findings, and other research discussed in this article, show that gender differences in colour preferences can be significant. It may be a mistake to assume that members of one sex can answer for the design preferences of the other. Research into gender differences has important implications for design, marketing, and brand management.

\section{CONCLUSIONS}

The two experiments reported in this article corroborate earlier findings and provide evidence that male and female design choices and preferences tend to differ systematically. We have discussed these findings in the context of other psychological gender differences, outlined 
some of the factors that may underlie these differences, and commented on some of the implications for marketing and brand management. A fuller understanding of these factors has the potential to provide companies with a significant competitive advantage.

\section{REFERENCES}

(1) Drucker, P. F. (1954) 'The practice of marketing', Harper and Row, New York.

(2) Brennan, R. (ed.) (1995). 'Cases in marketing management', Pitman Publishing, London;

Schiffman, L. G. and Kanuk, L. L. (1994) 'Consumer behavior’ (5th edition), Prentice-Hall, Englewood Cliffs, NJ.

(3) Popcorn, F. and Marigold, L. (2001). ‘EVEolution’, HarperCollins Business, London;

Tingley, J. C. and Robert, L. E. (1999) 'GenderSell’, Simon and Schuster, New York.

(4) Moss, G. (1995) 'Differences in the design aesthetic of men and women: Implications for product branding', Journal of Brand Management, Volume 3, Number 1, pp. 51-61; Moss, G. (1996) 'Sex: The misunderstood variable’, Journal of Brand Management, Volume 3, Number 5, pp. 296-305; Moss, G. (1999) Gender and consumer behaviour: Further explorations, Journal of Brand Management, Volume 7, Number 2, pp. 88-100.

(5) Cook, T. and Campbell, D. T. (1979) ‘Quasi-experimentation: Design and analysis issues for field settings', Rand McNally, Chicago, IL, chapter 3.

(6) Rosenthal, R. (1966) 'Experimenter effects in behavioral research’, Appleton-CenturyCrofts, New York; Rosenthal, R. and Rubin, D. B. (1978) 'Interpersonal expectancy effects: The first 345 studies', Behavioral and Brain Sciences, Volume 3, pp. 377-386; Ambady, N. and Rosenthal, R. (1996) 'Experimenter effects', in A. S. R. Manstead and M. Hewstone (eds), ‘The Blackwell encyclopedia of social psychology’ (pp. 230-235), Blackwell, Oxford.

(7) Moss, G. (1996) op. cit.; Moss, G. (1999) op. cit.

(8) Popcorn, F. and Marigold, L. (2001) op. cit.; Moss, G. (1999) op. cit.

(9) ‘Greetings cards’ (2000) Keynote Publishers, Hampton.

(10) ibid., p. 39.

(11) Moss, G. (1996) op. cit.; Moss, G. (1999) op. cit. 
(12) Dane, F. C. (1995) 'Survey methods, naturalistic observations, and case-studies', in A. M. Colman (ed.), 'Psychological research methods and statistics' (pp. 78-91), Longman, London and New York.

(13) Rosenthal, R. and Rosnow, R. L. (eds) (1975) 'The volunteer subject', Wiley, New York.

(14) Cook, T. and Campbell, D. T. (1979) op. cit., pp. 74-80.

(15) Ballard, P. B. (1912) 'What London children like to draw', Journal of Experimental Pediatrics, Volume 3, pp. 185-197; Moss, G. (1996) op. cit.

(16) Majewski, M. (1978) 'The relationship between the drawing characteristics of children and their sex', unpublished doctoral dissertation, Illinois State University.

(17) Moss, G. (1999) op. cit.

(18). Crawford, M. and Unger, R. K. (1995) 'Gender issues in psychology’, In A. M. Colman (ed.) ‘Controversies in psychology’ (pp. 37-58), Longman, London and New York, p. 39. (19) Maccoby, E. E. and Jacklin C. N. (1974) 'The psychology of sex differences', Stanford University Press, Stanford CA.

(20) Basow, S. A. (1992) 'Gender stereotypes and roles’ (3rd edition), Brooks/Cole, Belmont, CA; Martin, C. L. (1995) 'Gender’, in A. S. R. Manstead and M. Hewstone (eds), ‘The Blackwell encyclopedia of social psychology’(pp. 253-258), Blackwell, Oxford. (21) Deaux, K. (1984) ‘From individual differences to social categories’, American Psychologist, Volume 39, pp. 105-116.

(22) Strayer, J. and Roberts, W. (1997) ‘Facial and verbal measures of children’s emotions and empathy', International Journal of Behavioral Development, Volume 20, pp. 627-649. (23) Kimura, D. (1992) 'Sex differences in the brain’, Scientific American, September, pp. 81-87.

(24) Williams, J. E. and Best, D. L. (1982) 'Measuring stereotypes: A thirty nation study’, Sage, Beverly Hills, CA.

(25) Bem, S. (1981) 'Gender schema theory: A cognitive account of sex typing', Psychological Review, Volume 88, pp. 354-364. 
(26) Kimura, D. (1992) op. cit.

(27) Gregory, R. L. (1998) 'Eye and brain: The psychology of seeing’ (5th edn), Oxford University Press, Oxford, p. 130.

(28) Zajonc, R. B. (1968) ‘Attitudinal effects of mere exposure’, Journal of Personality and Social Psychology Monograph Supplement, Volume 9, Part 2, pp. 1-27.

(29) Colman, A. M., Best, W. M., and Austen, A. J. (1986) 'Familiarity and liking: Direct tests of the preference-feedback hypothesis’, Psychological Reports, Volume 58, pp. 931938; Colman, A. M., Sluckin, W., and Hargreaves, D. J. (1981) 'The effect of familiarity on preferences for surnames', British Journal of Psychology, Volume 72, pp. 363-369; Colman, A. M., Hargreaves, D. J., and Sluckin, W. (1981) 'Preferences for Christian names as a function of their experienced familiarity', British Journal of Social Psychology, Volume 20, pp. 3-5.

(30) Voyle, S. (2001) 'Next’s founder to fashion Marks and Spencer look', Financial Times, 3 February, p. 1. 
TABLE 1 NUMBERS OF RESPONDENTS PREFERRING FEMALE-DESIGNED AND MALE-DESIGNED CHRISTMAS CARDS

RESPONDENT PREFERENCES

Female respondents Male respondents

Female designer

Male designer
24

11
7

23




\section{TABLE 2 SUMMARY OF DIFFERENCES BETWEEN MALE AND FEMALE DESIGNS}

\section{Characteristic}

Linearity

Colour

Technicality

Three-dimensionality

Function versus aesthetics

Representation of human forms

\section{Male/female differences}

Male work more linear; fewer

rounded shapes

Women more interested in and

adventurous with colour

Male work more technical

Male work more three-

dimensional

Men more concerned with

function, women with aesthetics

Men and women tend to depict

own sex 


\section{Figure captions}

Figure 1. Representative business cards from a male designer (a) and a female designer (b) in Experiment I.

Figure 2. The four Christmas cards used in Experiment II: (a) and (b) were designed by men; (c) and (d) were designed by women . 
Figure 1

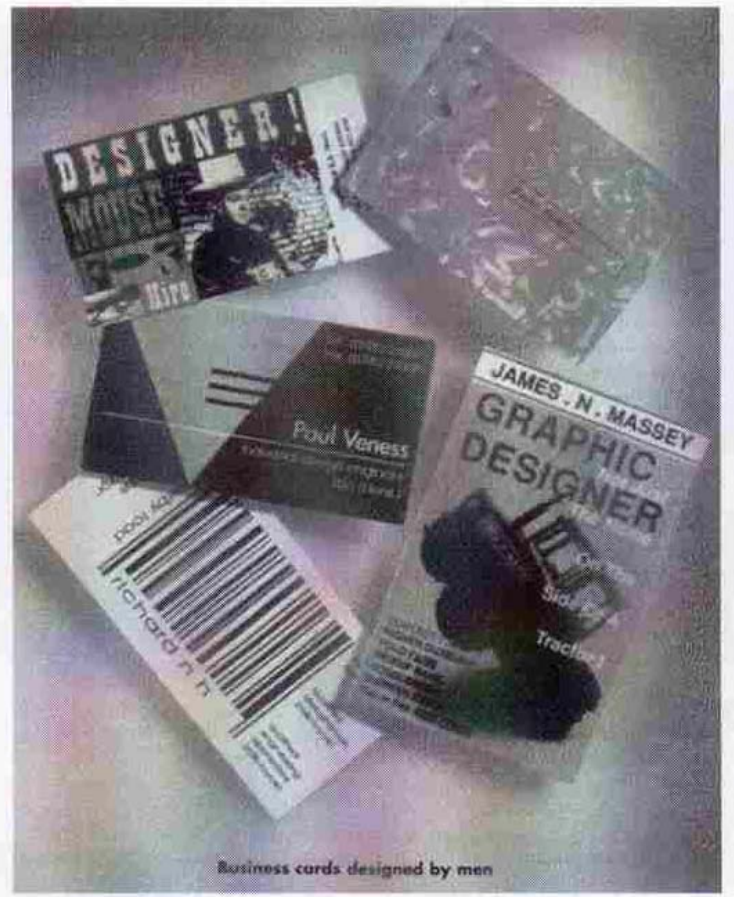

(a)

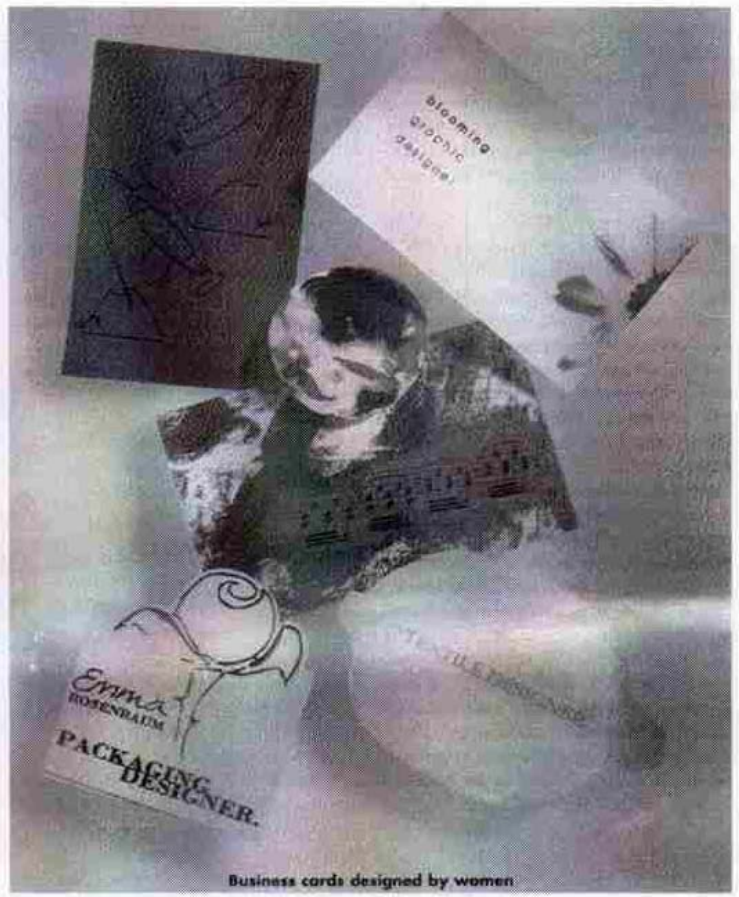

(b) 
Figure 2

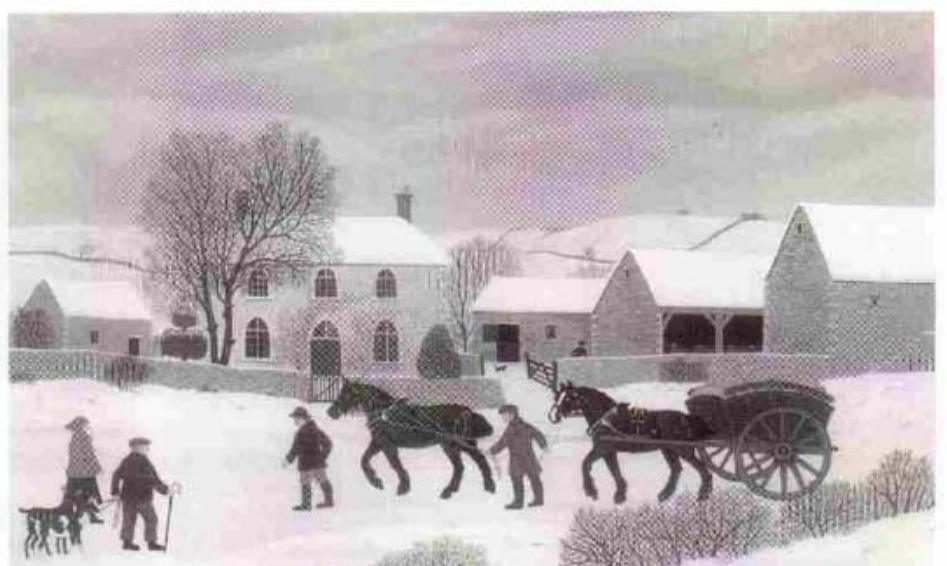

Hoveray

(a)

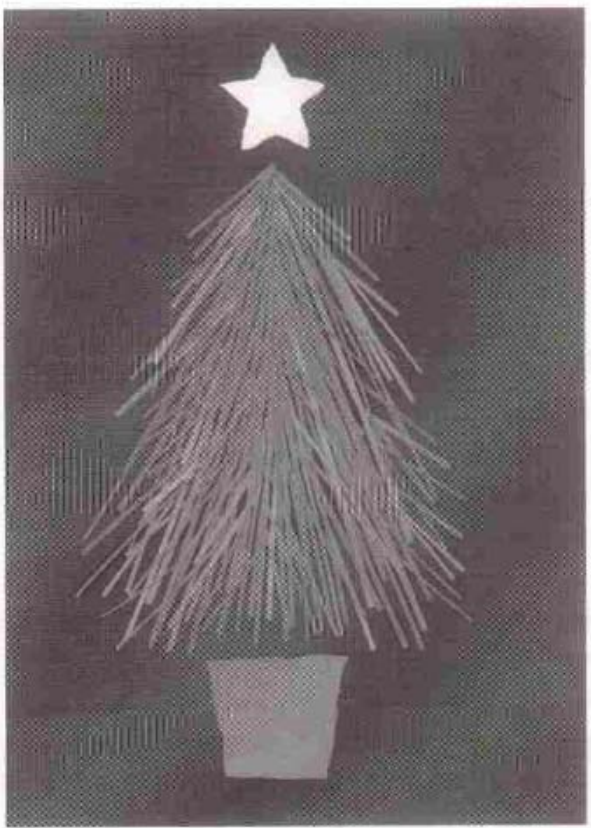

(b)

\section{(2)}

(c)

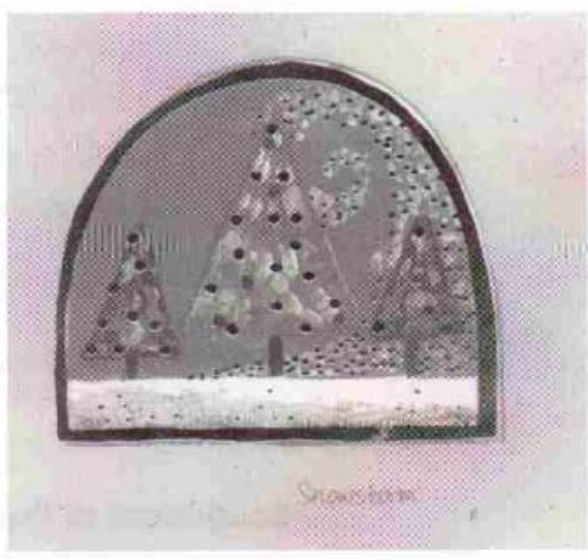

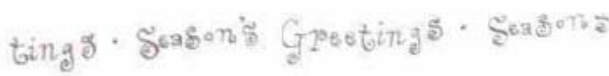

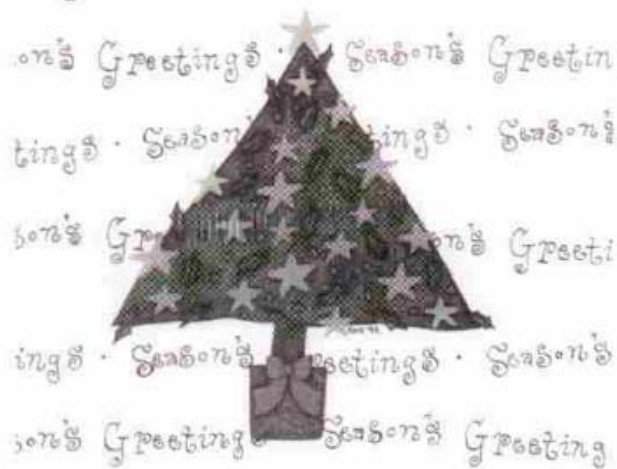

(d) jinge. Soasorg Grostings. Sergon? 